\title{
PEMODELAN SUKU BUNGA, KURS, IMPOR DAN EKSPOR DENGAN MENGGUNAKAN VECM
}

\author{
Nina Valentika*, ${ }^{1}$ Vivi Iswanti Nursyirwan ${ }^{2}$, Muhamad Syazali ${ }^{3}$, Irfani Azis ${ }^{4}$, \\ Syarif Abdullah ${ }^{5}$ \\ 1, 2, 4 Universitas Pamulang, \\ ${ }^{3}$ Universitas Pertahanan Indonesia \\ ${ }^{5}$ Universitas Sultan Ageng Tirtayasa \\ dosen02339@unpam.ac.id*1, dosen02226@unpam.ac.id², \\ muhamad.syazali@idu.ac.id ${ }^{3}$, dosen02639@unpam.ac.id ${ }^{4}$, \\ abdullahsyarifayis@gmail.com ${ }^{5}$ \\ *Corresponding Author
}

Received 25 August 2020; revised 26 March 2021; accepted 14 April 2021.

\begin{abstract}
ABSTRAK
Penelitian ini memodelkan variabel tingkat suku bunga, kurs rupiah, jumlah nilai impor dan jumlah nilai ekspor. Analisis metode Vector Error Correction Model (VECM) yang digunakan dalam penelitian ini untuk memodelkan variabel tingkat suku bunga, kurs rupiah, jumlah nilai impor dan jumlah nilai ekspor. Model untuk variabel ekspor, impor, suku bunga dan kurs dalam penelitian ini adalah VECM dengan lag 2, menggunakan trend deterministic dengan asumsi none intercept no trend, dan terdapat 1 kointegrasi. Dengan menggunakan MAPE, diperoleh bahwa model penelitian VECM tersebut sangat baik untuk meramalkan ekspor, kurs dan impor, sedangkan model penelitian VECM tersebut dikatakan layak untuk meramalkan tingkat suku bunga.
\end{abstract}

Kata kunci: ekspor, impor, kurs, suku bunga, VECM.

\begin{abstract}
This study model the variable interest rate, rupiah exchange rate, total import value, and total export value. Analysis of the Vector Error Correction Model (VECM) method used in this study to model the variables of interest rates, rupiah exchange rates, total import values, and total export values. The model for the variables of exports, imports, interest rates, and exchange rates in this study is VECM with a lag of 2, using a deterministic trend assuming none intercept no trend, and there is 1 cointegration. By using MAPE, it is found that the VECM research model is very good for predicting exports, exchange rates, and imports, while the VECM research model is said to be feasible for predicting interest rates.
\end{abstract}


Keywords: export, import, exchange rate, interest rate, VECM.

\section{PENDAHULUAN}

Analisis dalam ilmu ekonomi yang menjelaskan gambaran keseluruhan tentang kegiatan ekonomi disebut teori makroekonomi (Tandelilin 2010). Variabel makroekonomi diantaranya adalah jumlah nilai ekspor, jumlah nilai impor, tingkat suku bunga, dan kurs rupiah. Perekonomian yang semakin terbuka disebabkan arus globalisasi dan liberalisasi menimbulkan kekhawatiran bagi suatu negara. Hal ini disebabkan arus globalisasi dan liberalisasi juga dapat membawa konsekuensi pada fundamental perekonomian suatu negara. Ketidakmampuan negara dalam menjaga fundamental perekonomian akan membawa dampak ketidakstabilan ekonomi makro suatu negara (Mukhlis, 2013). Mengejar pertumbuhan ekonomi yang tinggi dan berkelanjutan merupakan salah satu perhatian bagi suatu negara, terlebih bagi negara berkembang dalam mencapai target perkembangan ekonominya (Karabou, 2017).

Harga merupakan acuan dalam suatu perdagangan international. Setiap negara dalam menunjukan harga diperlukan mata uang yang harus menyesuaikan dengan mata uang negara lain atau negara partner. Kurs memainkan peran penting dalam perdagangan internasional. Menurut Chou (2000) bahwa kondisi naik turunnya nilai tukar menunjukkan besarnya volatilitas, dimana volatilitas yang semakin besar menunjukan pergerakan kurs semakin besar yaitu terjadinya apresiasi/depresiasi. Kondisi tersebut dipengaruhi oleh faktor ekonomi maupun non ekonomi baik domestic maupun luar negeri. Faktor-faktor tersebut berupa juga faktor fundamental, faktor teknis dan faktor sentimen pasar.

Ekspor adalah pembelian negara lain ke atas barang buatan perusahaanperusahaan di dalam negeri (Tandelilin, 2010). Penjualan barang/jasa dari daerah pabean menurut ketentuan peraturan perundang-undangan yang berlaku disebut ekspor (Tambun, Palar, \& Rompas, 2014). Barang impor adalah barang yang dibeli dari luar negeri (Tandelilin, 2010). Impor adalah tindakan membawa barang atau komoditas dari satu negara ke negara lain secara sah berdasarkan ketentuan hukum perdagangan internasional. Hal penting dalam perdagangan internasional untuk memenuhi kebutuhan rakyat adalah kegiatan impor (Benny, 2013). 
Suku bunga yang berlebihan mempengaruhi nilai sekarang dari arus kas perusahaan, sehingga peluang investasi tidak lagi menarik. Suku bunga yang tinggi juga menaikan biaya modal yang harus dibayarkan oleh perusahaan. Tingkat pengembalian yang disyaratkan investor dari suatu investasi akan menaikan disebabkan oleh tingkat bunga yang berlebihan. Sinyal negatif terhadap harga saham adalah tingkat bunga berlebihan. Persyaratan atas investasi pada suatu saham adalah tingkat suku bunga. Investor menarik investasinya pada saham dan memindahkannya pada investasi berupa tabungan atau deposito disebabkan oleh tingkat suku bunga yang menaik (Tandelilin, 2010).

Nilai tukar atau kurs adalah banyaknya mata uang lokal yang diperlukan, yaitu jumlah Rupiah yang diperlukan untuk mendapatkan satu unit mata uang asing (Sukirno, 2010). Sinyal positif bagi perekonomian yang mengalami inflasi adalah naiknya nilai tukar rupiah terhadap mata uang asing. Peningkatan nilai tukar rupiah terhadap mata uang asing mengakibatkan penurunan biaya impor bahan baku untuk produksi dan tingkat suku bunga yang berlaku (Tandelilin, 2010). Kurs rupiah terhadap US\$ adalah salah satu indikator makroekonomi dalam penyusunan Anggaran Pendapatan dan Belanja Negara (APBN). Kurs rupiah saling terkait dengan indikator makro lain. Kurs dipengaruhi oleh ekspor, impor dan inflasi (Sukirno, 2010).

Ekspor, impor, dan inflasi terhadap kurs rupiah diteliti oleh Silitonga, dkk (2017). Regresi linear berganda digunakan dalam Silitonga, dkk (2017). Ekspor dan impor berpengaruh negatif dan signifikan terhadap variabel kurs rupiah atas US\$ serta inflasi tidak signifikan terhadap variabel kurs rupiah atas US\$ ditemukan oleh Silitonga, dkk (2017). Salah satu penelitian terkait peramalan lain adalah Vulandari dan Parwitasari (2018). Vulandari dan Parwitasari (2018) memprediksi tinggi muka air sungai bengawan solo. Penelitian Catalbas (2016) menggunakan Variance Decomposition, Granger Causality dan Analisis ImpulseResponse. Nilai tukar nominal, impor, dan ekspor di Turki menggunakan data tiga bulanan diteliti oleh Catalbas (2016). Variance decomposition, Granger Causality dan Analisis Impulse-Response digunakan dalam Catalbas (2016). Nilai tukar tidak memiliki pengaruh yang signifikan terhadap ekspor, impor, dan neraca 
perdagangan, dan langkah-langkah pembatasan impor berdampak buruk pada ekspor oleh Catalbas (2016).

Catalbas (2016) dimodifikasi dengan menambahkan variabel suku bunga. Penelitian ini menggunakan Vector Autoregression (VAR), Vector Autoregression in difference form (VARD) atau Vector Error Correction Model (VECM) untuk menguji hubungan antarvariabel. Sehingga, penelitian ini memodelkan variabel suku bunga, kurs, impor dan ekspor.

\section{METODE PENELITIAN}

Penelitian ini menggunakan analisis data sekunder. Periode data bulanan yang digunakan dalam penelitian ini adalah Januari 2009 sampai dengan Desember 2019. Pada penelitian ini ada 4 variabel yaitu: jumlah nilai ekspor, jumlah nilai impor, tingkat suku bunga, dan kurs rupiah. Jenis dan sumber data pada penelitian ini adalah data sekunder yaitu data yang bersumber dari publikasi laman resmi dari Bank Indonesia (BI) dan Badan Pusat Statistik (BPS).

Pendekatan kajian dalam penelitian ini menggunakan pengujian secara statistik dengan menggunakan software $R$. Langkah penelitian ini adalah

1. Melihat pergerakan data bulanan nilai ekspor, jumlah nilai impor, suku bunga dan kurs rupiah.

2. Periksa kestasioneran data dengan uji Augmented Dickey-Fuller (ADF).

3. Pemilihan lag yang bernilai Schwarz Information Criterion (SIC) terkecil.

4. Jika data stasioner, modelnya adalah VAR dengan ordo p. Jika data tidak stasioner, uji kointegrasi Johansen. Jika rank kointegrasi $(r)=0$, maka digunakan model VAR ordo $p$ dengan pembedaan. Tetapi jika $r>0$, maka model yang digunakan adalah model VECM ordo $p$ rank $r$.

5. Estimasi parameter pada model $\operatorname{VAR}(p), \operatorname{VARD}(p)$ atau $\operatorname{VECM.~}$

6. Menguji diagnostik model.

7. Melakukan peramalan dan mengevaluasi dengan memperhatikan Mean Absolute Percent Error (MAPE). 


\section{HASIL PENELITIAN DAN PEMBAHASAN}

\section{Stasioneritas Data}

Data tidak stasioner termasuk ke dalam salah satu masalah data deret waktu. Sehingga diperlukan tes formal untuk memeriksa apakah data itu stasioner atau tidak. Penelitian ini menggunakan uji ADF. Hasil tes data stasioner pada level dengan taraf nyata 5\% disajikan pada Tabel 1.

Tabel 1. Hasil Tes Data Stasioner pada Level

\begin{tabular}{llll}
\hline \multicolumn{1}{c}{ Variabel } & t-Statistic & \multicolumn{2}{c}{ Titik kritis } \\
& & MacKinnon 5\% level & Hasil \\
\hline Impor & -2.507625 & -3.448021 & Tidak Stasioner \\
Ekspor & -3.948239 & -3.444756 & Stasioner* \\
Kurs & -4.196178 & -3.444756 & Stasioner* \\
Tingkat Suku Bunga & -2.189573 & -3.445030 & Tidak Stasioner \\
\hline *stasioner pada level dengan taraf nyata 5\% &
\end{tabular}

Berdasarkan Tabel 1 diperoleh bahwa, variabel ekspor dan kurs yang stasioner pada level dengan taraf nyata 5\%. Hasil tes data stasioner pada first difference pada tingkat nyata 5\% disajikan pada Tabel 2.

Tabel 2. Hasil Tes Data Stasioner pada First Difference

\begin{tabular}{llll}
\hline \multicolumn{1}{c}{ Variabel } & t-Statistic & \multicolumn{2}{c}{ Titik kritis } \\
& & MacKinnon 5\% level & Hasil \\
\hline Impor & -2.443620 & -3.448021 & Tidak Stasioner \\
Ekspor & -11.86077 & -3.445030 & Stasioner* \\
Kurs & -8.789074 & -3.444756 & Stasioner* \\
Tingkat Suku Bunga & -7.061221 & -3.444756 & Stasioner* \\
\hline
\end{tabular}

*stasioner pada first difference dengan taraf nyata 5\%

Berdasarkan Tabel 2, variabel ekspor, kurs dan tingkat suku bunga stasioner pada first difference dengan taraf nyata 5\%. Hasil tes data stasioner pada second difference pada tingkat nyata 5\% disajikan pada Tabel 3. 
Nina Valentika, Vivi Iswanti Nursyirwan, Muhamad Syazali, Irfani Azis, Syarif Abdullah

Tabel 3. Hasil Tes Data Stasioner pada Second Difference

\begin{tabular}{llll}
\hline \multicolumn{1}{c}{ Variabel } & t-Statistic & \multicolumn{2}{c}{ Titik kritis } \\
& & MacKinnon 5\% level & Hasil \\
\hline Impor & -6.864874 & -3.448681 & Stasioner* \\
Ekspor & -7.114187 & -3.448021 & Stasioner* \\
Kurs & -14.27714 & -3.445308 & Stasioner* \\
Tingkat Suku Bunga & -17.44473 & -3.445030 & Stasioner* \\
\hline
\end{tabular}

*stasioner pada second difference dengan taraf nyata 5\%

Berdasarkan Tabel 3, diperoleh bahwa semua variabel stasioner pada second difference dengan taraf nyata $5 \%$.

\section{Lag Optimum}

Sistem VAR yang stasioner mendapatkan lag maksimum. Lag maksimum yang didapatkan adalah 15. Lag optimum penelitian ini adalah lag bernilai Schwarz Information Criterion (SIC) terkecil. Pencarian lag optimum disajikan pada Tabel 4.

Tabel 4. Pencarian Lag Optimum

\begin{tabular}{cc}
\hline Lag & SIC \\
\hline 0 & -16.30926 \\
1 & -17.38638 \\
2 & $-17.77844^{*}$ \\
3 & -17.66412 \\
4 & -17.51190 \\
5 & -17.16920 \\
6 & -16.76981 \\
7 & -16.27555 \\
8 & -15.94780 \\
9 & -15.57072 \\
10 & -15.12787 \\
11 & -15.06187 \\
12 & -14.65547 \\
\hline
\end{tabular}




\begin{tabular}{cc}
\hline Lag & SIC \\
\hline 13 & -14.23512 \\
14 & -13.86040 \\
15 & -13.50336
\end{tabular}

* mengindikasikan urutan orde dipilih berdasarkan kriteria SIC

Tabel 4 menunjukkan bahwa nilai SIC terkecil pada lag 2. Akibatnya, penelitian ini menggunakan lag 2.

\section{Uji Kointegrasi}

Pemilihan asumsi trend deterministic ditentukan sebelum pengujian kointegrasi. Hasil pemilihan asumsi trend deterministic untuk model disajikan pada Tabel 5.

Tabel 5. Hasil Penentuan Asumsi Trend Deterministic

\begin{tabular}{|c|c|c|c|c|}
\hline None & None & Linear & Linear & Quadratic \\
\hline No Intercept & Intercept & Intercept & Intercept & Intercept \\
\hline No Trend & No Trend & No Trend & Trend & Trend \\
\hline$-19.32327 *$ & $-19.32327 *$ & -19.21704 & -19.21704 & -19.10412 \\
\hline-19.19668 & -19.19730 & -19.12814 & -19.09275 & -18.98811 \\
\hline-18.97162 & -18.98002 & -18.94162 & -18.88216 & -18.81205 \\
\hline-18.70325 & -18.70846 & -18.70305 & -18.64974 & -18.61319 \\
\hline-18.40188 & -18.40213 & -18.40213 & -18.37165 & -18.37165 \\
\hline
\end{tabular}

*asumsi yang dipilih berdasarkan SIC

Berdasarkan Tabel 5, diperoleh bahwa SIC disarankan menggunakan trend deterministic dengan asumsi none no intercept no trend dan asumsi none intercept no trend. Penelitian ini menggunakan trend deterministic asumsi none intercept no trend karena model yang dihasilkan memiliki nilai adjusted $R$-squared terbesar. Pengujian kointegrasi dilakukan dengan menggunakan uji kointegrasi Johansen. Pengujian kointegrasi yang berdasarkan pada uji Trace. Hasil pengujian kointegrasi johansen disajikan pada Tabel 6. 
Nina Valentika, Vivi Iswanti Nursyirwan, Muhamad Syazali, Irfani Azis, Syarif Abdullah

Tabel 6. Hasil Pengujian Kointegrasi Johansen

\begin{tabular}{|c|c|c|c|c|}
\hline Hypothesized & & Trace & 0.05 & \\
\hline No. of $C E(s)$ & Eigenvalue & Statistic & Critical Value & Probability \\
\hline None & 0.191907 & 56.12504 & 54.07904 & 0.0325 \\
\hline At most 1 & 0.114657 & 28.63790 & 35.19275 & 0.2139 \\
\hline At most 2 & 0.065272 & 12.92832 & 20.26184 & 0.3696 \\
\hline At most 3 & 0.032190 & 4.220804 & 9.164546 & 0.3802 \\
\hline
\end{tabular}

Berdasarkan Tabel 6, diperoleh bahwa trace test menunjukkan adanya 1 kointegrasi yang signifikan pada taraf nyata 5\%.

\section{Model VECM}

Model antar variabel dalam penelitian ini adalah VECM dengan lag 2, menggunakan trend deterministic dengan asumsi none intercept no trend, dan terdapat 1 kointegrasi. VECM antar variabel makroekonomi memiliki 4 model yang masing-masing variabel sebagai variabel dependen. Berdasarkan Breusch Pagan-Godfrey, diperoleh bahwa semua model memiliki ragam sisaan homogen pada taraf nyata 1\%. Berdasarkan Breusch-Godfrey Serial Correlation LM Test, diperoleh bahwa semua model tidak ada auto korelasi atau korelasi serial antara sisaan. VECM dengan ekspor sebagai variabel target sebagai berikut:

$$
\begin{aligned}
\Delta \text { EKSPOR }_{t}= & -0.176172 *\left(\mathrm{IMPOR}_{t-1}+5.038902 * \mathrm{SUKUBUNGA}_{t-1}\right. \\
& -0.118940 * \mathrm{EKSPOR}_{t-1}+0.200943 * \mathrm{KURS}_{t-1} \\
& -22.72637)+0.147217 * \Delta \mathrm{IMPOR}_{t-1}-0.109966 \\
& * \Delta \mathrm{IMPOR}_{t-2}-2.537816 * \Delta \mathrm{SUKUBUNGA}_{t-1}+0.626386 \\
& * \Delta \mathrm{SUKUBUNGA}_{t-2}-0.805750 * \Delta \mathrm{EKSPOR}_{t-1} \\
& -0.058151 * \Delta \mathrm{EKSPOR}_{t-2}+0.433074 * \Delta \mathrm{KURS}_{t-1} \\
& -0.368241 * \Delta \mathrm{KURS}_{t-2}
\end{aligned}
$$

Tabel 7 adalah hasil estimasi VECM ekspor sebagai variabel target.

Tabel 7. Hasil Estimasi VECM Ekspor sebagai Variabel Target

\begin{tabular}{cc}
\hline Variabel & Keofisien \\
\hline Persamaan koinegrasi & $-0.176172^{*}$ \\
$\Delta$ IMPOR $_{t-1}$ & 0.147217 \\
\hline
\end{tabular}




\begin{tabular}{cc}
\hline Variabel & Keofisien \\
\hline$\Delta$ IMPOR $_{t-2}$ & -0.109966 \\
$\Delta$ SUKUBUNGA $_{t-1}$ & -2.537816 \\
$\Delta$ SUKUBUNGA $_{t-2}$ & 0.626386 \\
$\Delta$ EKSPOR $_{t-1}$ & $-0.805750^{*}$ \\
$\Delta$ EKSPOR $_{t-2}$ & -0.058151 \\
$\Delta$ KURS $_{t-1}$ & 0.433074 \\
$\Delta$ KURS $_{t-2}$ & -0.368241
\end{tabular}

*signifikan secara statistik pada taraf nyata 5\%

Berdasarkan Tabel 7, diperoleh bahwa koefisien pada persamaan kointegrasi bernilai negatif $(-0.176172)$ dan signifikan pada taraf nyata 5\%. Hal ini menunjukkan bahwa terdapat hubungan keseimbangan jangka panjang peubahpeubah yang terdapat pada persamaan kointegrasi terhadap perubahan ekspor yaitu impor, suku bunga, ekspor, dan kurs yang masing-masing satu periode sebelumnya. Berdasarkan Tabel 7, diperoleh pula bahwa perubahan ekspor dua periode sebelumnya memengaruhi perubahan ekspor pada taraf nyata 5\%.

VECM dengan impor sebagai variabel target adalah sebagai berikut:

$$
\begin{aligned}
\text { IIMPOR }_{t}= & -0.205847 *\left(\text { IMPOR }_{t-1}+5.03890200201 * \text { SUKUBUNGA }_{t-1}\right. \\
& -0.11893953632 * \text { EKSPOR }_{t-1}+0.200943164966 \\
& \left.* K U R S_{t-1}-22.7263676435\right)-0.483336 * \Delta \mathrm{IMPOR}_{t-1} \\
& -0.515311 * \Delta \mathrm{IMPOR}_{t-2}-2.007673 * \Delta \text { SUKUBUNGA }_{t-1} \\
& +0.647520 * \Delta \text { SUKUBUNGA }_{t-2}-0.192656 * \Delta \mathrm{EKSPOR}_{t-1} \\
& +0.303051 * \Delta \mathrm{EKSPOR}_{t-2}+0.280308 * \Delta \mathrm{KURS}_{t-1} \\
& -0.421764 * \Delta \mathrm{KURS}_{t-2}
\end{aligned}
$$

Tabel 8 adalah hasil estimasi VECM impor sebagai variabel target.

Tabel 8. Hasil Estimasi VECM Impor sebagai Variabel Target

\begin{tabular}{cc}
\hline Variabel & Keofisien \\
\hline Persamaan koinegrasi & $-0.205847^{*}$ \\
$\Delta \mathrm{IMPOR}_{t-1}$ & $-0.483336^{*}$ \\
$\Delta \mathrm{IMPOR}_{t-2}$ & $-0.515311^{*}$ \\
\hline
\end{tabular}




\begin{tabular}{cc}
\hline Variabel & Keofisien \\
\hline$\Delta$ SUKUBUNGA $_{t-1}$ & -2.007673 \\
$\Delta$ SUKUBUNGA $_{t-2}$ & 0.647520 \\
$\Delta$ EKSPOR $_{t-1}$ & -0.192656 \\
$\Delta$ EKSPOR $_{t-2}$ & 0.303051 \\
$\Delta$ KURS $_{t-1}$ & 0.280308 \\
$\Delta$ KURS $_{t-2}$ & -0.421764 \\
\hline
\end{tabular}

*signifikan secara statistik pada taraf nyata 5\%

Berdasarkan Tabel 8, diperoleh bahwa koefisien pada persamaan kointegrasi bernilai negatif $(-0.205847)$ dan signifikan pada taraf nyata 5\%. Hal ini menunjukkan bahwa terdapat hubungan keseimbangan jangka panjang peubahpeubah yang terdapat pada persamaan kointegrasi terhadap perubahan ekspor yaitu impor, suku bunga, ekspor, dan kurs yang masing-masing satu periode sebelumnya. Berdasarkan Tabel 8, diperoleh pula bahwa perubahan impor satu periode sebelumnya memengaruhi perubahan ekspor pada taraf nyata 5\%. Perubahan impor dua periode sebelumnya memengaruhi perubahan ekspor pada taraf nyata $5 \%$.

VECM dengan kurs sebagai variabel target sebagai berikut:

$$
\begin{array}{rl}
\Delta \mathrm{KURS}_{t}=0 & 028009 *\left(\mathrm{IMPOR}_{t-1}+5.03890200201 * \mathrm{SUKUBUNGA}_{t-1}\right. \\
& -0.11893953632 * \mathrm{EKSPOR}_{t-1}+0.200943164966 \\
& \left.* \mathrm{KURS}_{t-1}-22.7263676435\right)-0.018661 * \Delta \mathrm{IMPOR}_{t-1} \\
& -0.006657 * \Delta \mathrm{IMPOR}_{t-2}+1.699985 * \Delta \mathrm{SUKUBUNGA}_{t-1} \\
& +0.713112 * \Delta \mathrm{SUKUBUNGA}_{t-2}-0.008644 * \Delta \mathrm{EKSPOR}_{t-1} \\
& +0.006110 * \Delta \mathrm{EKSPOR}_{t-2}+0.228487 * \Delta \mathrm{KURS}_{t-1} \\
& -0.198896 * \Delta \mathrm{KURS}_{t-2}
\end{array}
$$

Tabel 9 adalah hasil estimasi VECM kurs sebagai variabel target.

Tabel 9. Hasil Estimasi VECM Kurs sebagai Variabel Target

\begin{tabular}{cc}
\hline Variabel & Keofisien \\
\hline Persamaan koinegrasi & $0.028009^{*}$ \\
$\Delta \mathrm{IMPOR}_{t-1}$ & -0.018661 \\
$\Delta \mathrm{IMPOR}_{t-2}$ & -0.006657 \\
\hline
\end{tabular}




\begin{tabular}{cc}
\hline Variabel & Keofisien \\
\hline$\Delta$ SUKUBUNGA $_{t-1}$ & 1.699985 \\
$\Delta$ SUKUBUNGA $_{t-2}$ & 0.713112 \\
$\Delta$ EKSPOR $_{t-1}$ & -0.008644 \\
$\Delta$ EKSPOR $_{t-2}$ & 0.006110 \\
$\Delta$ KURS $_{t-1}$ & $0.228487^{*}$ \\
$\Delta$ KURS $_{t-2}$ & $-0.198896^{*}$
\end{tabular}

*signifikan secara statistik pada taraf nyata $5 \%$

Berdasarkan Tabel 9, diperoleh bahwa koefisien pada persamaan kointegrasi bernilai positif (0.028009) dan signifikan pada taraf nyata 5\%. Hal ini menunjukkan bahwa terdapat hubungan keseimbangan jangka panjang peubahpeubah yang terdapat pada persamaan kointegrasi terhadap perubahan kurs yaitu impor, suku bunga, ekspor, dan kurs yang masing-masing satu periode sebelumnya. Berdasarkan Tabel 9, diperoleh pula bahwa perubahan kurs satu periode sebelumnya mempengaruhi perubahan kurs pada taraf nyata 5\%. Perubahan kurs dua periode sebelumnya memengaruhi perubahan kurs pada taraf nyata $5 \%$.

VECM dengan tingkat suku bunga sebagai variabel target sebagai berikut:

$$
\begin{aligned}
\Delta \text { SUKUBUNGA }_{t} & =0.001567 *\left(\mathrm{IMPOR}_{t-1}+5.03890200201 * \mathrm{SUKUBUNGA}_{t-1}\right. \\
& -0.11893953632 * \mathrm{EKSPOR}_{t-1}+0.200943164966 * \mathrm{KURS}_{t-1} \\
& -22.7263676435)+0.001648 * \Delta \mathrm{IMPOR}_{t-1}+0.001304 \\
& * \Delta \mathrm{IMPOR}_{t-2}+0.373697 * \Delta \mathrm{SUKUBUNGA}_{t-1}+0.147944 \\
& * \Delta \text { SUKUBUNGA }_{t-2}+0.003874 * \Delta \mathrm{EKSPOR}_{t-1}+0.001116 \\
& * \Delta \mathrm{EKSPOR}_{t-2}+0.002987 * \Delta \mathrm{KURS}_{t-1}+0.000928 * \Delta \mathrm{KURS}_{t-2}
\end{aligned}
$$

Tabel 10 adalah hasil estimasi VECM suku bunga sebagai variabel target.

Tabel 10. Hasil Estimasi VECM Suku Bunga sebagai Variabel Target

\begin{tabular}{cc}
\hline Variabel & Keofisien \\
\hline Persamaan koinegrasi & 0.001567 \\
$\Delta$ IMPOR $_{t-1}$ & 0.001648 \\
$\Delta$ IMPOR $_{t-2}$ & 0.001304 \\
$\Delta$ SUKUBUNGA $_{t-1}$ & $0.373697^{*}$ \\
\hline
\end{tabular}




\begin{tabular}{cc}
\hline Variabel & Keofisien \\
\hline$\Delta$ SUKUBUNGA $_{t-2}$ & 0.147944 \\
$\Delta$ EKSPOR $_{t-1}$ & 0.003874 \\
$\Delta$ EKSPOR $_{t-2}$ & 0.001116 \\
$\Delta$ KURS $_{t-1}$ & 0.002987 \\
$\Delta$ KURS $_{t-2}$ & 0.000928
\end{tabular}

*signifikan secara statistik pada taraf nyata 5\%

Berdasarkan Tabel 10, diperoleh bahwa koefisien pada persamaan kointegrasi tidak signifikan pada taraf nyata 5\%. Hal ini menunjukkan bahwa tidak terdapat hubungankeseimbangan jangka panjang peubah-peubah yang terdapat pada persamaan kointegrasi terhadap perubahan suku bunga yaitu impor, suku bunga, ekspor, dan kurs yang masing-masing satu periode sebelumnya. Berdasarkan Tabel 10, diperoleh pula bahwa perubahan suku bunga satu periode sebelumnya memengaruhi perubahan suku bunga pada taraf nyata 5\%.

Persamaan kointegrasi (model long-run) sebagai berikut:

$$
\begin{aligned}
\text { ect }_{t-1}=1.0000 \text { impor }_{t-1}+5.038902 \text { sukubunga }_{t-1} \\
-0.118940 \text { ekspor }_{t-1}+0.200943 \text { kurs }_{t-1}-22.72637
\end{aligned}
$$

Hasil estimasi VECM untuk hubungan keseimbangan jangka panjang disajikan pada Tabel 11.

Tabel 11. Hasil Estimasi VECM untuk Hubungan Keseimbangan Jangka Panjang

\begin{tabular}{ccc}
\hline Variabel & Koefisien & t-statistics \\
\hline impor $_{t-1}$ & 1.0000 & \\
sukubunga $_{t-1}$ & 5.038902 & 1.67704 \\
ekspor $_{t-1}$ & -0.118940 & -0.52134 \\
kurs $_{t-1}$ & 0.200943 & 1.22429 \\
Konstanta & $-22.72637^{*}$ & -3.69814 \\
\hline
\end{tabular}

* signifikan secara statistik pada taraf nyata $5 \%$

Berdasarkan Tabel 11 diperoleh bahwa tidak ada variabel yang berpengaruh terhadap impor dalam jangka panjang. Adapun forecasting model untuk meramalkan ekspor disajikan pada Tabel 12. 
Tabel 12. Forecasting Model untuk Meramalkan Ekspor

\begin{tabular}{lcc}
\hline \multicolumn{1}{c}{ Bulan } & Hasil Peramalan & Hasil Analitik \\
\hline Januari 2020 & 23.51543 & 23.33569 \\
Februari 2020 & 23.51543 & 23.3667 \\
Maret 2020 & 23.51544 & 23.3672 \\
April 20 & 23.51544 & 23.2217 \\
Mei 2020 & 23.51544 & 23.0779 \\
Juni 2020 & 23.51544 & 23.2108 \\
\hline
\end{tabular}

Berdasarkan Tabel 12, model penelitian untuk meramalkan ekspor memiliki MAPE sebesar 1.08\%. Berdasarkan Maricar (2019), MAPE yang kurangdari 10\%, kemampuan model sangat baik. Sehingga, model penelitian ini sangat baik untuk meramalkan ekspor. Adapun forecasting model untuk meramalkan kurs disajikan pada Tabel 13.

Tabel 13. Forecasting Model untuk Meramalkan Kurs

\begin{tabular}{lcc}
\hline \multicolumn{1}{c}{ Bulan } & Hasil Peramalan & Hasil Analitik \\
\hline Januari 2020 & 9.061141 & 9.5275 \\
Februari 2020 & 9.061141 & 9.53069 \\
Maret 2020 & 9.06114 & 9.62869 \\
April 2020 & 9.06114 & 9.67202 \\
Mei 2020 & 9.06114 & 9.60953 \\
Juni 2020 & 9.061139 & 9.560712 \\
\hline
\end{tabular}

Berdasarkan Tabel 13, model penelitian untuk meramalkan kurs memiliki MAPE sebesar 5,49\%. Berdasarkan Maricar (2019), kemampuan model penelitian ini sangat baik untuk meramalkan kurs. Adapun forecasting model untuk meramalkan tingkat suku bunga disajikan pada Tabel 14.

Tabel 14. Forecasting Model untuk Meramalkan Tingkat Suku Bunga

\begin{tabular}{lcc}
\hline \multicolumn{1}{c}{ Bulan } & Hasil Peramalan & Hasil Analitik \\
\hline Januari 2020 & 0.057603 & 0.05 \\
Februari 2020 & 0.057603 & 0.0475 \\
Maret 2020 & 0.057603 & 0.045 \\
\hline
\end{tabular}


Nina Valentika, Vivi Iswanti Nursyirwan, Muhamad Syazali, Irfani Azis, Syarif Abdullah

\begin{tabular}{ccc}
\hline Bulan & Hasil Peramalan & Hasil Analitik \\
\hline April 2020 & 0.057603 & 0.045 \\
Mei 2020 & 0.057602 & 0.045 \\
Juni 2020 & 0.057602 & 0.0425 \\
\hline
\end{tabular}

Berdasarkan Tabel 14, model penelitian untuk meramalkan tingkat suku bunga memiliki MAPE sebesar 26\%. Berdasarkan Maricar (2019), jika range MAPE diantara 20\% hingga 50\%, kemampuan model peramalan layak. Sehingga, kemampuan model penelitian ini layak untuk meramalkan tingkat suku bunga. Adapun forecasting model untuk meramalkan impor disajikan pada Tabel 15.

Tabel 15. Forecasting Model untuk Meramalkan Impor

\begin{tabular}{lcc}
\hline \multicolumn{1}{c}{ Bulan } & Hasil Peramalan & Hasil Analitik \\
\hline Januari 2020 & 23.41224 & 23.38133 \\
Februari 2020 & 23.41224 & 23.1698 \\
Maret 2020 & 23.41224 & 23.3149 \\
April 2020 & 23.41224 & 23.2518 \\
Mei 2020 & 23.41225 & 22.8565 \\
Juni 2020 & 23.41225 & 23.0995 \\
\hline
\end{tabular}

Berdasarkan Tabel 15, model penelitian untuk meramalkan impor memiliki MAPE sebesar 1,01\%. Berdasarkan Maricar (2019), kemampuan model penelitian ini sangat baik untuk meramalkan impor.

\section{SIMPULAN}

Simpulan penelitian ini adalah model untuk variabel ekspor, impor, suku bunga dan kurs adalah VECM dengan lag 2, menggunakan trend deterministic dengan asumsi none intercept no trend, dan terdapat 1 kointegrasi. Dengan menggunakan MAPE, diperoleh bahwa model penelitian VECM tersebut sangat baik untuk meramalkan ekspor, kurs dan impor, sedangkan model penelitian VECM tersebut dikatakan layak untuk meramalkan tingkat suku bunga. 


\section{UCAPAN TERIMA KASIH}

Penulis mengucapkan terima kasih kepada reviewer atas kritik dan saran untuk peningkatan kualitas artikel ini, dan kepada tim redaksi atas perbaikan pada tampilan artikel ini. Terima kasih juga penulis sampaikan kepada semua pihak yang terlibat dalam penyusunan sampai diterbitkannya artikel ini, yaitu Program Studi Matematika Universitas Pamulang, Program Studi S-1 Akuntansi Universitas Pamulang, Program Studi Matematika Universitas Pertahanan Indonesia, Program Studi Teknik Mesin Universitas Sultan Ageng Tirtayasa, Bank Indonesia, dan Badan Pusat Statistik yang telah bersedia menjalin kerjasama dan memberikan fasilitas sehingga penelitian dapat terlaksana dengan baik.

\section{DAFTAR PUSTAKA}

Benny, J. (2013). Ekspor dan impor pengaruhnya terhadap posisi cadangan devisa di Indonesia. Jurnal EMBA, 1(4), 1406-1415.

Catalbas N. (2016). The relationship among nominal exchange rate, import, and export in Turkey for the period 1988:1 to 2015:3. International Research Journal of Applied Finance, 7(4), 11-25.

Chou, W. L. (2000). Exchange rate variability and China's export. Journal of Comparative Economics, 28(1), 61-79. https://doi.org/10.1006/jcec.1999.1625.

Karabou, E. F. (2017). Exports and economic growth in Togo. Journal of Economics and International Finance, 9(3), 19-29. https://doi.org/10.5897/JEIF2017.0832.

Maricar, M. A. (2019). Analisa perbandingan nilai akurasi moving average dan exponential smoothing untuk sistem peramalan pendapatan pada perusahaan xyz. Jurnal Sistem dan Informatika (JSI), 13(2), 36-45.

Mukhlis, I. (2013). Analisis volatilitas nilai tukar mata uang rupiah terhadap dolar. Journal of Indonesia Applied Economics, 5(2), 172-182.

Silitonga, R. B. R., Ishak, Z., \& Mukhlis. (2017). Pengaruh ekspor, impor, dan inflasi terhadap nilai tukar rupiah di Indonesia. Jurnal Ekonomi Pembangunan, 15(1), 53-39.

Sukirno, S. (2010). Makro ekonomi teori pengantar. Edisi ke-tiga. Jakarta: Rajawali Pers.

Tambun, N., Palar, S., \& Rompas, W. (2014). Analisis struktur dan kinerja ekspor komoditas pertanian pasca krisis ekonomi di Sulawesi Utara. Jurnal Berkala Ilmiah Efisien, 14(3), 82-93.

Tandelilin, E. (2010). Portofolio dan investasi teori dan aplikasi. Yogyakarta: Kanisius.

Vulandari R. T., \& Parwitasari T. A. (2018). Perbandingan model AR(1), ARMA(1), dan ARIMA(1,1,1) pada prediksi tinggi muka air sungai bengawan Solo pada pos pemantauan jurug. MUST: Journal of 
Nina Valentika, Vivi Iswanti Nursyirwan, Muhamad Syazali, Irfani Azis, Syarif Abdullah

Mathematics Education, Science and Technology, 3(1), 46-56. http://dx.doi.org/10.30651/must.v3i1.1620. 